\title{
Atomoxetine Induced Obsessive-Compulsive Disorder
}

\author{
Mengühan Araz Altay ${ }^{*}$ \\ ${ }^{1}$ Department of Child and Adolescent Psychiatry, Trakya University Faculty of Medicine, Edirne, Turkey
}

*Corresponding Author: Mengühan Araz Altay, M.D., Assistant Professor, Department of Child and Adolescent Psychiatry, Trakya University Faculty of Medicine, Şükrüpaşa Mah. Seha Sk. No: 3, D: 39 22030, Edirne, Turkey. Tel: +90-5321689363, Email: menguhanarazaltay@gmail.com

Received September 22, 2018; Accepted December 20, 2018; Online Published January 26, 2019

\begin{abstract}
Introduction: Attention deficit and hyperactivity disorder (ADHD) is a common neurodevelopmental disorder in children and adolescents. Atomoxetine is a non-stimulant drug used in the treatment of ADHD.

Case Presentation: In this article, a case of obsessive-compulsive disorder (OCD) which occurred in an 11-year-old boy with an increased dose of atomoxetine during ADHD treatment and disappeared with dose reduction is reported. This case is only the second OCD case resulting from the use of atomoxetine.

Conclusion: The case reported herein is the second case caused by the use of atomoxetine and the first in which OCD symptoms regressed when the atomoxetine dose was reduced. OCD development due to atomoxetine consumption may occur at different doses. When OCD develops, the solution may be dose reduction, or it may be necessary to discontinue treatment with atomoxetine.

Keywords: Atomoxetine Hydrochloride, Obsessive-Compulsive Disorder, Attention Deficit Disorder with Hyperactivity, Child Psychiatry
\end{abstract}

\section{Introduction}

Attention deficit and hyperactivity disorder (ADHD), a common neurodevelopmental disorder, is being diagnosed with gradually increasing frequency. It is reported at the rate of $5 \%$ in children. The clinical picture of $\mathrm{ADHD}$ manifests itself with inattention and hyperactivityimpulsivity that disturb the functionality or development of an individual. ${ }^{1}$ Since the symptoms affect social and academic achievement and physical condition, treatment is often required; pharmacological agents, both stimulants and nonstimulants, are frequently used in its treatment. ${ }^{2}$ Atomoxetine is a selective, presynaptic, norepinephrine reuptake inhibitor also known as a NET inhibitor. It was the first non-stimulant medication to receive FDA approval for the treatment of $\mathrm{ADHD} .^{3}$ In this article, a case in which atomoxetine was initiated due to ADHD and OCD developed during the treatment is reported.

\section{Case Presentation}

An 11-year-old male patient was brought to our polyclinic by his family with complaints of school failure, hyperactivity, and attention deficit. As a result of a psychiatric evaluation, he was diagnosed with "ADHD, mixed type". The patient's family history revealed that his mother had an anxiety disorder, his aunt had a diagnosis of obsessive-compulsive disorder (OCD), and both had received drug treatment. The patient had a height of $140 \mathrm{~cm}$, body weight of 25 $\mathrm{kg}$, and blood pressure of 100/65 mm Hg. His routine laboratory and cardiac evaluations were found to be normal. Long-acting methylphenidate at a dose of $18 \mathrm{mg} / \mathrm{d}$ was initiated for the patient but discontinued because the patient had intense agitation, anorexia, retreating, and paranoid thoughts after methylphenidate treatment. Treatment with $10 \mathrm{mg} /$ day atomoxetine was initiated one month later, after the disappearance of these symptoms. An atomoxetine dose of $18 \mathrm{mg} / \mathrm{d}$ was initiated upon the absence of any side effect and the partial reduction of symptoms in the first-month control. In the control performed 1 month later, the patient complained of being unable to be sure, having obsessive thoughts of being seriously ill and dying, needing constant suggestions, asking repeated questions, and receiving only temporary relief when answers were given that started 3 days after the dose of atomoxetine was increased. The patient's mother indicated that these complaints intensified especially in the evening hours and lasted for many hours. Based on DSM5 criteria, the patient was diagnosed with OCD attributed to atomoxetine, and the drug treatment was discontinued.

Copyright (C) 2019 The Author(s). This is an open-access article distributed under the terms of the Creative Commons Attribution License (http:// creativecommons.org/licenses/by/4.0), which permits unrestricted use, distribution, and reproduction in any medium, provided the original work is properly cited. 
The treatment of $10 \mathrm{mg}$ atomoxetine was again initiated for the patient whose OCD symptoms improved markedly 1 week after drug discontinuation. One month later, during the control of the patient, the partial regression of ADHD symptoms and no OCD symptoms were observed.

\section{Discussion}

ADHD is a neurodevelopmental disorder frequently seen in children and adolescents. Previous studies have reported that it coexists with many psychiatric diseases and that this coexistence may be due to common structural and functional disorders., ${ }^{4,5}$ One of the most common disorders coexisting with $\mathrm{ADHD}$ is special learning disorder. ${ }^{6}$ These two disorders have been reported to originate from the same specific gene. ${ }^{5}$ Furthermore, ADHD, OCD, autism, and schizophrenia are also described as neurodevelopmental frontostriatal disorders due to the presence of common functional and structural abnormalities in cortico-striatal ami-cortical structures. ${ }^{7}$ The amount of evidence regarding the coexistence of ADHD and sleep disorder has recently been increasing. Therefore, ADHD should not be considered as a single disease but as a complex disorder associated with other potential psychiatric disorders. Atomoxetine, a nonstimulant drug used in the treatment of $\mathrm{ADHD}$, is the selective blocker of presynaptic norepinephrine carriers in the central nervous system. ${ }^{3}$ There are reports that the use of atomoxetine in the presence of depression, anxiety, tic disorder, or nocturnal enuresis coexisting with ADHD has possible advantages. ${ }^{8-10}$

The use of atomoxetine is known to cause side effects such as headache, sleep disorders, increases in blood pressure, cardiac problems, suicidal tendencies, and restlessness. ${ }^{8,11}$ However, in the literature, only 1 case report has indicated that atomoxetine causes OCD. In that case, OCD symptoms did not occur at $25 \mathrm{mg} / \mathrm{d}$ and $40 \mathrm{mg} / \mathrm{d}$ doses of atomoxetine; it was observed only when the dose was increased to $60 \mathrm{mg} / \mathrm{d}$. OCD symptoms continued although a $40 \mathrm{mg} / \mathrm{d}$ dose of atomoxetine was initiated for the patient, and it was reported that OCD symptoms disappeared with the discontinuation of atomoxetine. ${ }^{12}$ OCD symptoms were also observed in the current case as a result of dose increase similar to the previously reported case; however, unlike the previously reported case, OCD was observed at a very low dose $(18 \mathrm{mg} / \mathrm{d})$, and the symptoms were not repeated with dose reduction.

In OCD patients, an increased dopaminergic function was detected in the brain. ${ }^{13}$ Atomoxetine is a noradrenaline reuptake (NET) inhibitor. It also increases extracellular levels of dopamine in the prefrontal cortex, believed to result from NET inhibition. ${ }^{14}$ Studies have reported the coexistence of OCD and ADHD to be common. ${ }^{15}$ In the present case, a child with ADHD who may be predisposed to OCD, atomoxetine, which is the NET inhibitor, may have triggered OCD symptoms by increasing dopaminergic activity in the prefrontal cortex.

\section{Conclusion}

The case reported herein is the second one caused by the use of atomoxetine. When these two cases are evaluated, OCD development due to atomoxetine may occur at different doses, and when OCD develops, dose reduction may be the solution, or the discontinuation of atomoxetine may be necessary. Clinicians should be careful when considering an atomoxetine-OCD association.

\section{Conflict of Interest Disclosures}

None to be declared.

\section{Ethical Approval}

Written informed consent was obtained from the relatives.

\section{References}

1. American Psychiatric Association (APA). Diagnostic and Statistical Manual of Mental Disorders (DSM-5R). 5th ed. Washington, DC: American Psychiatric Association Publishing 2013. doi:10.1176/appi.books.9780890425596.

2. Brown KA, Samuel S, Patel DR. Pharmacologic management of attention deficit hyperactivity disorder in children and adolescents: a review for practitioners. Transl Pediatr. 2018;7(1):36-47. doi:10.21037/tp.2017.08.02.

3. Yu G, Li GF, Markowitz JS. Atomoxetine: A Review of Its Pharmacokinetics and Pharmacogenomics Relative to Drug Disposition. J Child Adolesc Psychopharmacol. 2016;26(4):314-326. doi:10.1089/cap.2015.0137.

4. Altay MA. Sleep Disorders and Attention Deficit: A Consequence of Proinflammatory State? J Clin Sleep Med. 2018;14(6):1081. doi:10.5664/jcsm.7190.

5. Willcutt EG, Pennington BF, Smith SD, et al. Quantitative trait locus for reading disability on chromosome $6 p$ is pleiotropic for attention-deficit/hyperactivity disorder. Am J Med Genet. 2002;114(3):260-268. doi:10.1002/ajmg.10205.

6. Altay MA, Gorker I. Assessment of Psychiatric Comorbidity and WISC-R Profiles in Cases Diagnosed with Specific Learning Disorder According to DSM-5 Criteria. Noro Psikiyatr Ars. 2018;55(2):127-134. doi:10.5152/npa.2017.18123.

7. Bradshaw JL, Sheppard DM. The neurodevelopmental frontostriatal disorders: evolutionary adaptiveness and anomalous lateralization. Brain Lang. 2000;73(2):297-320. doi:10.1006/brln.2000.2308.

8. Childress AC. A critical appraisal of atomoxetine in the management of ADHD. Ther Clin Risk Manag. 2016;12:27-39. doi:10.2147/tcrm.s59270.

9. Allen AJ, Kurlan RM, Gilbert DL, et al. Atomoxetine treatment in children and adolescents with ADHD and comorbid tic disorders. Neurology. 2005;65(12):1941-1949. doi:10.1212/01.wnl.0000188869.58300.a7.

10. Shatkin JP. Atomoxetine for the treatment of pediatric nocturnal enuresis. J Child Adolesc Psychopharmacol. 2004;14(3):443447. doi:10.1089/cap.2004.14.443.

11. Pozzi M, Carnovale C, Peeters G, et al. Adverse drug events related to mood and emotion in paediatric patients treated for ADHD: A meta-analysis. J Affect Disord. 2018;238:161-178. doi:10.1016/j.jad.2018.05.021.

12. Ince C, Karakus M, Karadeniz S, Kandil S. A Case of Obsessive Compulsive Disorder Developing During Atomoxetine Use. Turk J Pediatr Dis. 2015;2:140-142.

13. Koo MS, Kim EJ, Roh D, Kim CH. Role of dopamine in the pathophysiology and treatment of obsessive-compulsive 
disorder. Expert Rev Neurother. 2010;10(2):275-290. doi:10.1586/ern.09.148.

14. Bymaster FP, Katner JS, Nelson DL, et al. Atomoxetine increases extracellular levels of norepinephrineand dopamine in prefrontal cortex of rat: a potential mechanism for efficacy in attention deficit/hyperactivity disorder. Neuropsychopharmacology. 2002;27(5):699-711. doi:10.1016/s0893-133x(02)00346-9.
15. Abramovitch A, Dar R, Mittelman A, Wilhelm S. Comorbidity Between Attention Deficit/Hyperactivity Disorder and Obsessive-Compulsive Disorder Across the Lifespan: A Systematic and Critical Review. Harv Rev Psychiatry. 2015;23(4):245-262. doi:10.1097/hrp.0000000000000050. 